Discussion

Papers

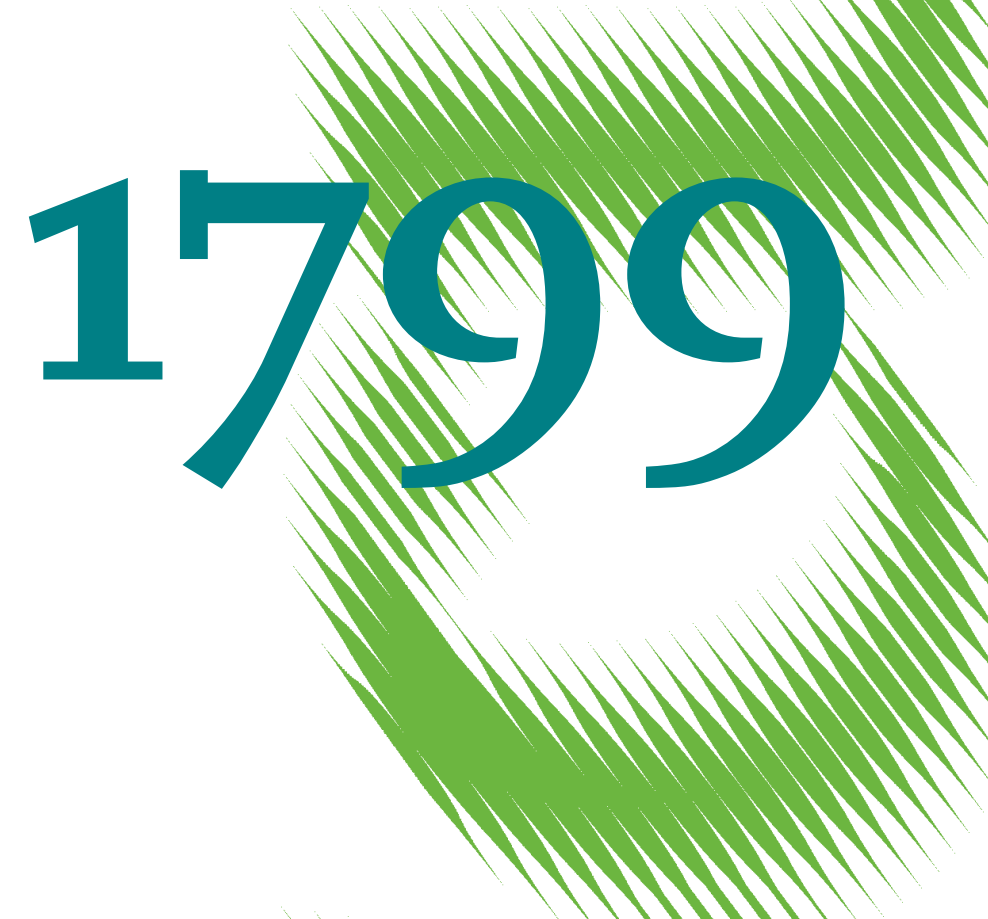

Gender Identity and Wives' Labor Market Outcomes in West and East Germany between 1984 and 2016 
Opinions expressed in this paper are those of the author(s) and do not necessarily reflect views of the institute.

IMPRESSUM

(C) DIW Berlin, 2019

DIW Berlin

German Institute for Economic Research

Mohrenstr. 58

10117 Berlin

Tel. +49 (30) $89789-0$

Fax +49 (30) $89789-200$

http://www.diw.de

ISSN electronic edition 1619-4535

Papers can be downloaded free of charge from the DIW Berlin website:

http://www.diw.de/discussionpapers

Discussion Papers of DIW Berlin are indexed in RePEc and SSRN:

http://ideas.repec.org/s/diw/diwwpp.html

http://www.ssrn.com/link/DIW-Berlin-German-Inst-Econ-Res.html 


\title{
Gender identity and wives' labor market outcomes in West and East Germany between 1984 and 2016
}

\author{
Maximilian Sprengholz ${ }^{1} \quad$ Anna Wieber ${ }^{2} \quad$ Elke Holst $^{3}$
}

\begin{abstract}
We exploit the natural experiment of German reunification in 1990 to investigate if the institutional regimes of the formerly socialist (rather gender-equal) East Germany and the capitalist (rather gender-traditional) West Germany shaped different gender identity prescriptions of family breadwinning. We use data for three periods between 1984 and 2016 from the representative German Socio-Economic Panel (SOEP). Density discontinuity tests and fixed-effects regressions suggest that married couples in West (but not East) Germany diminished the wife's labor market outcomes in order to avoid situations where she would earn more than him. However, the significance of the male breadwinner prescription seems to decline in West Germany since reunification, converging to the more gender-egalitarian East Germany. Our work emphasizes the view that political and institutional frameworks can shape fairly persistent gender identity prescriptions that influence household economic decisions for some time, even when these frameworks change.
\end{abstract}

Keywords: Gender identity, Male breadwinner norm, Institutions, Female labor market outcomes, SOEP

$J E L:$

J16, J12, D10

\footnotetext{
${ }^{1}$ DIW Berlin (until 31 ${ }^{\text {st }}$ January 2019), corresponding author, maximilian.sprengholz@hu-berlin.de

2 DIW Berlin (until 31 ${ }^{\text {st }}$ December 2014), Anna.Wieber@drv-bund.de

${ }^{3}$ DIW Berlin and University of Flensburg, eholst@diw.de

We are indebted to Francine Blau for invaluable comments. Additionally, we extend our thanks to Adam Lederer, Katharina Wrohlich, Maik Hamjediers, as well as conference participants for their feedback.
} 


\section{Introduction}

We exploit the natural experiment of German division and reunification to investigate how the institutional regimes of the formerly socialist East Germany and the capitalist West Germany shaped different gender identity prescriptions (Akerlof \& Kranton, 2000, 2010) in terms of family breadwinning. Based on representative longitudinal data on German married couples, we explore how men's breadwinner and women's homemaker role affect wives' labor market decisions in West and East Germany between 1984 and 2016. By scrutinizing if, and how, couples avoided situations where the wife out-earns her husband, we present evidence suggesting that the market economy of West Germany prior to reunification fostered a strong male breadwinner model, whereas the East German socialism did not. East Germany, being twice the receiver of imposed institutions, makes a case for the view that institutional settings shape domestic gender cultures.

We build on the theoretical and empirical approach of Bertrand et al. (2015) to measure the magnitude of the male breadwinner prescription using the distribution of income within households. For the U.S., Bertrand et al. found that the gender prescription 'a man should earn more than his wife' is visible as a sharp drop to the right of the 50 percent threshold in the density distribution of the wife's share of household incomewhere the wife starts to earn more than her husband. Because neither classic economic specialization nor marriage market models explain such a discontinuity, they took this as evidence that couples avoid the case where the wife out-earns her husband in order not to violate a male breadwinner prescription. Corroborating this interpretation, Bertrand et al.'s results also suggest that wives with a higher probability to out-earn their husbands are less likely to be in the labor force and earn less than their potential income. However, replications of their study return mixed results. Codazzi et al. (2017) confirmed that wives in Brazil distort their labor market outcomes to maintain gender identity conformity. Yet, no discontinuity in the wife's share of income is found for Sweden (Hederos Eriksson \& Stenberg, 2015), Finland or the U.S. (Binder \& Lam, 2018; Zinovyeva \& Tverdostup, 2018) after accounting for heaping issues at the 50 percent threshold. Consequently, these scholars argued that the estimated discontinuity by Bertrand et al. (2015) might be explained by an overrepresentation of equal-earning couples instead of a male breadwinner gender identity prescription. For this reason, Lippman et al. (2016) refrained from estimating a discontinuity test on the same German data we use in this paper. 
Our contribution is threefold. First, we account for the critique regarding the discontinuity test by ruling out alternative explanations for the heaping of a wife's relative income of just, but not more than, 50 percent. In this way, we argue, the discontinuity test of the distribution of the wife's relative income is a feasible indicator for the prevalence of a male breadwinner norm.

Second, we present evidence suggesting that the prevalence of male breadwinning as gender prescription is shaped by a country's institutional system. Studies using the discontinuity test (Bertrand et al., 2015; Binder \& Lam, 2018; Hederos Eriksson \& Stenberg, 2015; Codazzi et al., 2017; Zinovyeva \& Tverdostup, 2018) cannot isolate cultural from institutional effects on female labor market outcomes, because gender identity prescriptions are analyzed within a given political and statutory framework. Therefore, differences in prescriptions between countries might be a result of country-specific cultures as well as of welfare state characteristics and public policy, where specific relationships are difficult to disentangle (Nyman, Reinikainen, \& Stocks, 2013; Pfau-Effinger, 2012). Germany was divided in two states in 1949 (West: Federal Republic of Germany/FRG and East: German Democratic Republic/GDR), separated by the wall between 1961 and 1990, and reunited in 1990. This unique setting enables us to highlight how distinct institutions in West and East Germany shaped the male breadwinner model differently for people who shared the same history and culture before the division. We argue that during 40 years of separation, public policy and promoted ideologies regarding family models and female employment led to particular cultures concerning paid and unpaid work. Moreover, because the West German institutions were imposed on East Germany following reunification, we can examine how distinct gender identity prescriptions between East and West Germany persist under a common, and slowly emancipating, institutional system. We consider the periods 1984-1990 for West Germany and 1997-2006 as well as 2007-2016 for West and East Germany in the discontinuity test. Our results indicate that a male breadwinner prescription was only prevalent in West Germany, but not in East Germany. We found a sharp and significant drop at the point of equal earnings for West Germany for 1984-1990 and 1997-2006. The discontinuity for West Germany decreased continuously since 1984-1990 and was insignificant for 2007-2016, indicating that the aversion of West German couples to female breadwinning was most prevalent prior to reunification.

Third, we explore channels through which wives might have distorted their labor market outcomes to explain part of the observed discontinuity for West Germany. Using a 
couple-fixed effects model with lagged regressors, we examine if working women lose their breadwinner status by leaving employment or by reducing working hours subsequent to earning more than their husbands. We estimated that a wife who out-earned her husband in year $t-1$ was less likely to do so in year $t$ in West Germany for 1984-1990 (-8.6 pp.) and 1997-2006 (-6.4 pp.). We gathered no evidence that the decline in the wife's breadwinner probability is due to the wife leaving employment altogether. However, for 1984-1990, we found that a West German wife out-earning her husband in $t-$ 1 worked a significant 0.9 hours less per week in year $t$.

Our results suggest that country-specific political and institutional frameworks affect gender identity prescriptions. Since reunification, the male breadwinner prescription seems to have declined in significance in West Germany, converging to the consistently more gender egalitarian East Germany. This development may both be an effect of reunification as well as a general trend toward emancipation, including institutional changes in Germany. Thus, our work emphasizes the importance of simultaneous effects of persistent culture and current institutional frameworks on female labor market outcomes.

\section{Theoretical framework}

\subsection{Identity economics}

Akerlof and Kranton $(2000,2010)$ introduced the concept of a socially determined identity to economics. In their definition of identity, a person's sense of self encompasses a clear conception of social groups the person belongs to as well as how members of these groups should behave. By including this cognition into the individuals' utility function, identity can influence economic outcomes because deviating from prescribed behavior generates costs. In terms of gender, men and women tend to conform with their sense of self in terms of gender-specific behavioral prescriptions (similar to the sociological concept of 'doing gender', West \& Zimmerman, 1987). For instance, identity specific elements in the household context are 'wife' and 'husband'. In the male breadwinner model, the ideal husband plays the role of the breadwinner and the ideal wife is characterized as the homemaker (Akerlof \& Kranton, 2010, p. 93). Consequently, a wife having a comparative advantage at the market would not necessarily specialize in paid work - as proposed by Gary Becker's (1991) new household economic theory - because it would violate the gender identity prescription that 'a man should earn more than his wife' and, therefore, lead to a decline in the household's utility. 


\subsection{Breadwinning prescriptions in West and East Germany}

From an institutionalist perspective, family and labor market policies influence, among others, partner's labor market participation, the household division of labor as well as women's income shares within the household (Anxo, Fagan, Cebrian, \& Moreno, 2007; Gornick, 2004). In this way, institutional differences can substantially shape the development of domestic cultures and, hence, associated breadwinning prescriptions (Hummelsheim \& Hirschle, 2010; Pfau-Effinger \& Smidt, 2011). According to Bertrand et al. $(2015$, p. 572$)$, the prevalence of the male breadwinner prescription is reflected in the share of approval to the statement 'If a woman earns more than her husband, it is almost certain to cause problems' from the World Value Survey (WVS). In the WVS 19951998, a few years after German reunification in October 1990, agreement to the statement was significantly higher in West than East Germany (West 50.2\%, East 42.5\%, $p<$ 0.001 ). We take this difference in agreement as an indicator how country-specific institutional and ideological frameworks shaped distinct and persistent gender identity prescriptions in terms of family breadwinning - FRG (today West Germany) being rather gender traditional and the socialist GDR (today East Germany) being rather gender egalitarian (Rosenfeld, Trappe, \& Gornick, 2004).

In terms of institutional and cultural dimensions, the FRG is often understood as a state promoting the prototypical male breadwinner model (Aisenbrey \& Fasang, 2017). Traditional marriage and the single-earner family model was supported by various laws and policies introduced in the 1950s and 1960s (Trappe, Pollmann-Schult, \& Schmitt, 2015, p. 232), many of which are still valid in present day Germany. Examples include child allowance, the dependent coverage of the non-working partner for health insurance, and the joint taxation of married couples by the 'Ehegattensplitting. The Ehegattensplitting is a tax assessment procedure in which the income tax is imposed on half of the mutual income and then doubled. Due to the progressive income tax in Germany, this produces tax benefits for couples with unequal income while inducing negative employment incentives for second earners, increasing dependence (of predominantly women) on their working partner (Hipp, Bernhardt, \& Allmendinger, 2015). Moreover, the 1958 equal rights law in the FRG stated that the right of wives to be employed depended upon the compatibility of their labor with marriage and family duties, thus reinforcing the dominance of traditional marriage (Helwig, 1993). This law was not replaced until 1977, when both partners were permitted to participate in the labor force and to choose independently who is responsible for domestic work. In 1989, women's labor 
market participation rate was only 56 percent and considerably lower than men's (83\%) in the FRG (Rosenfeld et al., 2004, p. 111). Although legally equal in the right to work, the male breadwinner model was still dominant. In a 1991 poll, 25 percent of surveyed women in West Germany stated that homemaking was their 'dream job', in stark contrast to the 3 percent of East German women stating the same (Ute Gerhards, cited in Duggan, 1995, p. 184).

The family ideal was very different in the GDR. Women were generally expected to participate in the labor force; they were part of the socialist 'production' with full time employment seen as a norm for both men and women. Already in the 1950s, women's labor force was essential for the survival of the centrally planned economy of the GDR (Trappe et al., 2015). Facilitated by the extensive provision of public child care, the female labor force participation rate was 89 percent in 1989 (Rosenfeld et al., 2004, p. 111). However, despite the idea of a relative equality in the labor 'market', the model of equality was still patriarchal. The occupational segregation in the GDR resulted in a gender pay gap comparable to the FRG (Rosenfeld et al., 2004), women in the GDR provided far more housework than men, and women were responsible for reproductive tasks (Nickel, 1992). This 'Muttipolitik' ('mommy politics') is exemplified by a parental leave scheme only available to mothers as well as the monthly day off for women to catch up with housework (Duggan, 1995). However, although women were expected to be 'workers, mothers and housewives simultaneously', their increasing economic independence led to a devaluation of the male breadwinner norm (Trappe et al., 2015, p. 233; see also Trappe \& Sørensen, 2006). In 1987, women's average financial contribution to household income was 40 percent in the GDR compared to 18 percent in the FRG (Gottfried \& O'Reilly, 2002). Thus, at least in terms of female employment and income contributions within the household, the socialist GDR and its policies shaped rather egalitarian cultural and gender relations compared to the FRG.

However, gender identity prescriptions might have altered following reunification. Two different gender cultures interacted under a common - and changing - West German institutional frame. While several FRG policies supporting a traditional gender arrangement within the family remain in place (e.g. Ehegattensplitting, health insurance coverage of the dependent partner), at least some new or updated policies promote emancipated family models. Examples include the extended financial support and flexibility during parental leave, extra benefits for father's leave take-up ('Elterngeld') and the extension of the national childcare provision. The public gender equality discourse 
certainly also affects what is perceived as 'good' or 'adequate' behavior of women and men (Pfau-Effinger \& Smidt, 2011). Conceivably, gender-specific prescriptions may not only have become more egalitarian over time, but may also have converged between West and East Germany following reunification. In the WVS 2010-2014, agreement to the statement 'If a woman earns more than her husband, it is almost certain to cause problems' was nearly equal in West and East Germany (West $16.7 \%$ and East 16.2\%, $p=$ $0.39)$.

Still, general attitudes are not necessarily a good predictor of behavior (Steiber \& Haas, 2009). Additionally, institutional changes like work-family reconciliation policies introduced in unified Germany might foster gender equality in labor market outcomes, yet, evidence on this relationship is inconclusive (Brady, Blome, \& Kmec, 2019). The acceptance and success of new state policies might also depend on how these policies correspond to the prevailing gender culture (Hummelsheim \& Hirschle, 2010). On the one hand, there is evidence on converging gender arrangements between West and East Germany in terms of employment patterns and the household division of market and non-market work (Kelle, Simonson, \& Gordo, 2017; Rosenfeld et al., 2004; Trappe et al., 2015; Trappe \& Sørensen, 2006). On the other hand, East German women consistently show less support for a traditional breadwinner arrangement and a traditional division of household labor than West German women (Adler \& Brayfield, 1996; Cooke, 2007; Görges \& Beblo, 2015). The female labor force participation rate remains higher in East Germany, especially for mothers (Pfau-Effinger, 2012). Full-time employment is also more common among women in East Germany, accompanied by quicker returns into full-time employment after childbirth (Kelle et al., 2017). As a result, the (unadjusted) gender pay gap remains substantially lower in East compared to West Germany since the appreciation of East German employment following reunification (Destatis, 2019). Lee, Alwin and Tufis (2007) even reported that, although gender ideologies grew more egalitarian in both East and West Germany, they further diverged following reunification.

The recursive relationship between individual experience of and attitudes toward female employment (Steiber \& Haas, 2009, 2012) offers a plausible explanation why the East German domestic culture may affect the labor market outcomes of women beyond reunification. Because women in the GDR worked to a similar extent as their male partners and contributed a considerable share to the household income, they already lived an alternative to the traditional male breadwinner arrangement. Additionally, due to the 
widespread unemployment in East Germany following the economic turbulences of reunification, the importance of both partners being able to add to the common income remained important (Trappe \& Sørensen, 2006). Conceivably, the personal experience of the mutual economic interdependence of female and male partner further contributed to the devaluation of the male breadwinner model in East Germany (Cha \& Thébaud, 2009). Thus, even decades after reunification there might be differences between East and West Germany in how a male breadwinner prescription affects economic decisions of couples. For example, in a study sharing the German natural experiment setting with our paper, Lippmann et al. (2016) reported that wives who out-earned their husbands "did gender" by contributing more housework in West but not in East Germany using data between 1991 to 2012.

\subsection{Hypotheses}

The current state of research suggests that the gender identity prescription of a male breadwinner was considerably more prevalent in the FRG compared to the GDR. Consequently, following Akerlof and Kranton (2000), the losses in identity by violating the prescription that 'a man should earn more than his wife' have presumably been higher in the FRG, too. Thus, assuming some cultural stability beyond reunification, we argue that couples' economic decisions in the FRG/West Germany were characterized by maintaining conformity to a male breadwinner prescription, whereas the decisions of couples in the GDR/East Germany were not. That is, we expect that only wives in the (former) FRG diminished their labor market outcomes in order to avoid out-earning their husbands. Based on the reasoning and results of Bertrand et al. (2015), we presume that such conduct is visible as a discontinuity in the distribution of the wife's relative household income at 50 percent.

Hypothesis 1: The distribution of the wife's share of household labor income drops at the point of equal earnings of spouses (0.5) for West Germany but not for East Germany.

If couples avoid the wife's crossing of the 50 percent threshold of relative household income, how do they achieve that? Conceivably, those women (theoretically) being at risk of out-earning their husbands may either not work or earn less than their potential income to preserve gender identity conformity. Using the imputed likelihood of wives to 
out-earn their husbands as predictor (based on the median income of the wife's demographic group), the results of Bertrand et al. (2015) suggest this behavior. However, the sample size of our dataset does not allow for such an approach, which is why we exploit its panel character instead. We examine if wives diminish their labor market outcomes subsequent to out-earning their husbands (what Bertrand et al. do too in auxiliary estimations). Given that the-however originated-female breadwinning status violates the male breadwinner prescription, we assume that wives who earn more than their spouses attempt to recover gender identity conformity. Two plausible ways for wives to reduce their income would be to either stop working or to adjust their working hours.

Hypothesis 2: A couple where the wife's income exceeds that of her husband subsequently attempts to restore gender identity conformity by (a) recovering a male breadwinner arrangement (husband earns more). They achieve that by the wife (b) leaving employment, or (c) reducing working hours. Such behavior is only observable in West Germany.

By testing these two hypotheses, we can learn something about the effects of the male breadwinner prescription on female labor market outcomes. To highlight differences and possible time trends in this relationship for East and West Germany, we analyze both regions separately for various periods between 1984 and 2016. However, we only have individual level data for wives in the FRG and, therefore, can only attempt to deduce the prevalence of the male breadwinner model in the GDR from information surveyed in East Germany after reunification.

\section{Methodology}

\subsection{McCrary density discontinuity test}

We use a McCrary density discontinuity test (McCrary, 2008) to estimate the presumed drop at the 50 percent benchmark in the distribution of the wife's relative household income. The discontinuity is specified as

$$
\hat{\theta}=\ln \left(\hat{f}^{+}\right)-\ln \left(\hat{f}^{-}\right),
$$

where $f$ is the density of the running variable, $\hat{f}^{+}$and $\hat{f}^{-}$denote the local linear regression estimates right and left of the cut-off, based on the bin midpoints of an undersmoothed histogram (McCrary, 2008, p. 702). We follow Bertrand et al. (2015, p. 576) and estimate the discontinuity for the wife's share of household income to the right of 
the cut-off (at 0.50001). In order to ensure independence of the observations for the McCrary test, we account for the panel data structure of the SOEP by selecting the relative income of the median year for any wife within a given analysis period.

\subsection{Lagged fixed effects regressions}

We estimate panel regressions with lagged regressors to identify the means by which wives might attempt to restore gender identity conformity subsequent to earning more than their husbands. One major concern is that the wife's out-earning of her husband is conditional on unobserved characteristics of both spouses and, thus, might be endogenous. Couple fixed effects are included into the econometric model to control for time constant unobserved heterogeneity. The following linear regression model is specified

$$
\begin{aligned}
& \text { LaborMarketOutcome }_{i t}=\alpha_{i}+\beta_{1} \text { wifeEarnsMore } \\
& i, t-1 \\
&+\beta_{2} \boldsymbol{L}_{i, t-1}+\beta_{3} \boldsymbol{X}_{i t}+\epsilon_{i t},
\end{aligned}
$$

where LaborMarketOutcome $_{\text {it }}$ is a placeholder for the dependent variables (1) wifeEarnsMore $_{i t}$, a dummy indicating if wife $i$ earns more in year $t$, (2) wifeEMP it , a dummy indicating if wife $i$ is employed in any month in year $t$, and (3) wifeWorkHoursit, containing the weekly contractual working hours of wife $i$ at the time of the interview in year $t$. The dichotomous regressor wifeEarnsMore ${ }_{i, t-1}$ equals 1 if wife $i$ earned more than her husband at $t-1$.

The intuition of including wifeEarnsMore also as regressand is to capture the 'gross' effect of a wife's out-earning of her husband in year $t-1$ on her probability to out-earn him in year $t$. The dependent variables wifeEMP and wifeWorkHours, then, enable us to investigate possible channels through which a wife might attempt to recover a male breadwinner arrangement in the couple. We use contractual (not actual) working hours to directly map the income effect of a working hours reduction. Although wifeEarnsMore and wifeEMP are dummy variables, we refrain from estimating a fixed-effects logit model to use a maximum of available observations within the linear probability setting.

$\boldsymbol{L}_{i, t-1}$ is a vector of lagged control variables, containing cubic polynomials of the logarithm of the wife's and the husband's annual income, an interaction between the wife's and the husband's annual log income, and the share of imputed income values for both wife and husband-all at $t-1$. We do not use the wife's share of household income as covariate because using ratios in regression models may introduce bias, even when including all ratio constituents (Kronmal, 1993). The interaction between husband's and 
wife's income, however, allows for varying effects of relative income contributions of spouses. $\boldsymbol{X}_{t}$ contains additional standard controls at $t$ : dummies for age groups of 5 years for both spouses, a set of dummy variables that indicate the age of the youngest child in the household (see online appendix Section B for details), the county level unemployment rate at the month of the interview, and a set of dummy variables for the survey year - all at $t$. The district level unemployment rate is added to control for economic effects that may influence the income of wives and husbands differently (e.g. via shorttime work) as well as their employment decisions. We report panel robust standard errors clustered on couple level to account for the panel structure of our data.

\section{Data}

Our estimations are based on the German Socio-Economic Panel (SOEP) spanning the years between 1984 and 2016 (v33.1, doi:10.5684/soep.v33.1; for a detailed description see Wagner, Frick, \& Schupp, 2007). The SOEP is a representative longitudinal study of private households with nearly 11,000 households and about 30,000 persons sampled annually. The data provide information on all household members. Since 1984, the same private households, persons, and families have been surveyed annually in West Germany and since 1990 in East Germany. This enables us to consider the years between 1984 and 1990 preceding the reunification for West Germany, and twenty years for both West and East Germany, split into two decades beginning in 1997 and 2007, respectively. For comparability, we omit the years 1991-1996 from our analysis. Those years directly after the reunification were shaped by great economic turbulences in East Germany due to the transition into the West German economic and political system, presumably affecting the scope for economic decision-making of wives (Trappe \& Sørensen, 2006).

We restrict our base sample to married women where both spouses are between twenty-five and sixty-four years old. In addition, our main regressor wifeEarnsMore is only calculated for years in which both spouses have positive labor income and work at least one month; in which neither the woman nor the husband is in education, vocational training, parental leave or civil service; or receives pensions, unemployment, or social benefits. We presume that the intra-household income distribution can only be sensibly evaluated by the wife and her husband with regard to gender identity prescriptions when they compare their respective labor income. Moreover, we expect being in education, being a pensioner, being unemployed, or being on parental leave to be a dif- 
ferent determination base, even if the person in question may have positive labor income. We base our estimations on inflation-adjusted pre-tax income in 2016 Euros, defined as annual labor income from primary and secondary jobs as well as bonus payments. We do not consider monthly earnings because of their possible volatility within a survey year. We use imputed income data provided by the SOEP.

In the SOEP data, there is a substantial fraction of spouses who reported exactly the same income, leading to a spike in the distribution of the wife's relative household income at 50 percent. This is a problem because the McCrary discontinuity test is biased in the presence of heaping at the cut-off. Thus, any clustering at 50 percent of the relative income of wives would result in an overestimated discontinuity. This is also the reason why Zinovyeva and Tverdostup (2018) question the results of Bertrand et al. (2015), arguing that the estimated discontinuity may originate from spouses having the same income because of mutual family businesses or co-working. Similarly, using Swedish data, Hederos Eriksson and Stenberg (2015) no longer found a discontinuity at 50 percent after excluding couples with self-employed spouses from the analysis. We account for this critique by excluding all couples where at least one of the spouses is self-employed. Although there is no measure in the SOEP indicating if spouses are co-working, we impute this information and additionally exclude spouses who are working in the same industry, have the same occupation, and work in companies of the same size.

However, the remaining share of equal-earning spouses still amounts to a considerable 0.6 percent of working couples. As top-coded or imputed income values also do not explain the spike, we presume it to be a result of rounding behavior by survey respondents. In fact, rounded values are much less present in German administrative income tax data on jointly assessed couples (FAST 2010, doi: 10.21242/73111.2010.00.00.3.1.0) than in the SOEP. Therefore, we de-round the fraction of potentially rounded income values (integer multiples of $50,100,500,1000,5000$, and 10000) that exceeds the respective fraction in the administrative data. For example, if 1 percent of income values are an integer multiple of 100 in the SOEP, but only 0.3 percent in the tax data, then we de-round the 0.7 excess percentage points of income values. (A detailed account of the de-rounding procedure is provided in Section A of the online appendix.) By de-rounding, the share of equal-earning partners in the analysis sample is reduced to 0.2 percent. Because this is still slightly higher than the 0.1 percent in the tax data, we additionally delete the observations causing the remaining excess spike. We randomly determine which income values are de-rounded or deleted. To account for possible selection bias 
introduced by this process, we repeat every discontinuity test and regression 100 times with prior de-rounding and subsequent deletion of the remaining excess spike and average the estimated coefficients.

Another recently proposed explanation for the discontinuity in the distribution of the wife's relative household income at 50 percent is strategic misreporting in surveys to maintain gender identity conformity. For the U.S. and Switzerland, respectively, MurrayClose and Heggeness (2018) and Roth and Slotwinksi (2018) showed that spouses overreport the husband's income and underreport the wife's income if she earns more than him. We cannot specifically account for this possible caveat within the SOEP, however, we will discuss this possibility in light of our results. In any case, the discontinuity would be the effect of a male breadwinner prescription - either by wives actually earning less than their husbands or by at least stating to do so.

All restrictions applied, we are left with a total of $n=10,586$ working couples. Table 1 displays summary statistics of our main variables separately for West as well as East Germany for all considered periods. Not only were wives consistently less likely to be in employment than their male spouses, they also earned less when working. Still, there were important differences between East and West Germany that reflect their distinct history. On average, wives in East Germany between 1997 and 2006 contributed 44 percent to the household labor income working 34.7 hours per week, whereas wives in West Germany contributed just 28 percent working 24.9 hours. Consequently, female breadwinners were more prevalent in East Germany in this period: Only 11 percent of wives earned more than their husbands in West Germany but 34 percent in East Germany. This picture remains largely unchanged for the period between 2007 and 2016.

The employment rates of wives rose continuously in West Germany since reunification (50\% to $72 \%$ ), but the share of wives out-earning their husbands remains remarkably small (2007-2016: 11\%). This development is most likely an effect of the increased share of part-time working women, corresponding to the decline of weekly working hours. However, whereas these figures suggest a departure from the single earner model in West Germany, they do not clearly reflect a trend toward less prevalence of the male breadwinner prescription. 
Table 1. Summary statistics of main variables by region and period

\begin{tabular}{|c|c|c|c|c|c|c|c|c|c|c|}
\hline & \multicolumn{2}{|c|}{$\begin{array}{c}\text { West Germany } \\
1984-1990\end{array}$} & \multicolumn{2}{|c|}{$\begin{array}{l}\text { West Germany } \\
\text { 1997-2006 }\end{array}$} & \multicolumn{2}{|c|}{$\begin{array}{l}\text { West Germany } \\
2007-2016\end{array}$} & \multicolumn{2}{|c|}{$\begin{array}{c}\text { East Germany } \\
1997-2006\end{array}$} & \multicolumn{2}{|c|}{$\begin{array}{l}\text { East Germany } \\
2007-2016\end{array}$} \\
\hline & Mean & Std. Dev. & Mean & Std. Dev & Mean & Std. Dev & Mean & Std. Dev & Mean & Std. Dev \\
\hline \multicolumn{11}{|l|}{ Working couples } \\
\hline \multicolumn{11}{|l|}{ Husband } \\
\hline Annual labor income (gross) & 25652.74 & 14358.22 & 40754.42 & 23399.33 & 46745.17 & 27166.88 & 28451.98 & 14940.17 & 34122.93 & 18750.31 \\
\hline Weekly working hours (contractual) & 40.35 & 4.99 & 39.26 & 6.17 & 39.55 & 6.00 & 40.55 & 5.33 & 40.20 & 5.33 \\
\hline \multicolumn{11}{|l|}{ Wife } \\
\hline Annual labor income (gross) & 11226.22 & 9765.46 & 17109.78 & 14031.03 & 20047.45 & 17032.03 & 21955.08 & 11059.31 & 24795.72 & 14385.34 \\
\hline Weekly working hours (contractual) & 27.79 & 11.21 & 24.89 & 11.17 & 24.92 & 11.29 & 34.66 & 7.66 & 33.42 & 8.57 \\
\hline Wife's share of household income (gross) & 0.29 & 0.16 & 0.28 & 0.17 & 0.29 & 0.18 & 0.44 & 0.14 & 0.42 & 0.16 \\
\hline Wife earns more & 0.08 & 0.28 & 0.11 & 0.31 & 0.11 & 0.32 & 0.34 & 0.47 & 0.33 & 0.47 \\
\hline $\mathrm{N}$ & \multicolumn{2}{|c|}{6,657} & \multicolumn{2}{|c|}{13,322} & \multicolumn{2}{|c|}{17,995} & \multicolumn{2}{|c|}{3,944} & \multicolumn{2}{|c|}{4,146} \\
\hline $\mathrm{n}$ & \multicolumn{2}{|c|}{1,981} & \multicolumn{2}{|c|}{3,644} & \multicolumn{2}{|c|}{5,450} & \multicolumn{2}{|c|}{943} & \multicolumn{2}{|c|}{1,076} \\
\hline \multicolumn{11}{|l|}{ All couples } \\
\hline \multicolumn{11}{|l|}{ Husband } \\
\hline Employed & 0.87 & 0.34 & 0.83 & 0.38 & 0.88 & 0.33 & 0.75 & 0.43 & 0.82 & 0.38 \\
\hline \multicolumn{11}{|l|}{ Wife } \\
\hline Employed & 0.50 & 0.50 & 0.61 & 0.49 & 0.72 & 0.45 & 0.66 & 0.47 & 0.77 & 0.42 \\
\hline$N$ (couple-years) & \multicolumn{2}{|c|}{19,124} & \multicolumn{2}{|c|}{34,997} & \multicolumn{2}{|c|}{41,618} & \multicolumn{2}{|c|}{10,584} & \multicolumn{2}{|c|}{10,009} \\
\hline$N$ (couples) & \multicolumn{2}{|c|}{3,962} & \multicolumn{2}{|c|}{7,242} & \multicolumn{2}{|c|}{10,393} & \multicolumn{2}{|c|}{1,935} & \multicolumn{2}{|c|}{2,188} \\
\hline
\end{tabular}

Note: 'Working couples' refers to the base specification outlined in this section. 'All couples' refers to all married couples between age 25 and 64 in the data. Income related statistics are based on (once) de-rounded income values. Income reported in Euro. As the annual income is calculated based on answers by survey respondents in the subsequent year, income related statistics for the period $2007-$ 2016 are based on annual incomes between 2007 and 2015. 
Further, the low number of female breadwinners in West Germany also limits the power of the panel regressions because the within-variation of wifeEarnsMore is rather small (see online appendix Section B for detailed panel summary statistics.). Nonetheless, most of the variables are available for at least three waves for each couple and, thus, are a good basis for a fixed effects panel regression.

\section{Results}

\subsection{The distribution of relative income}

Table 2 provides the discontinuity estimates for working couples. Figure 1 shows the corresponding distributions and the local linear regression smoother.

Table 2. Density discontinuity estimates working couples

\begin{tabular}{|c|c|c|c|c|c|c|c|c|c|c|}
\hline & \multicolumn{4}{|c|}{ West Germany } & \multicolumn{4}{|c|}{ East Germany } & \multicolumn{2}{|c|}{ West vs. East } \\
\hline & $\hat{\theta}$ & SE & \% Drop & $\mathrm{N}$ & $\hat{\theta}$ & SE & \% Drop & $\mathrm{N}$ & $\Delta \hat{\theta}$ & SE \\
\hline \multicolumn{11}{|l|}{ Decade } \\
\hline 1984-1990 & $-0.81 * * *$ & 0.15 & 55.39 & 1,829 & & & & & & \\
\hline 1997-2006 & $-0.26^{* *}$ & 0.11 & 22.98 & 3,593 & 0.04 & 0.18 & -4.23 & 919 & 0.30 & 0.24 \\
\hline \multirow[t]{2}{*}{ 2007-2016 } & -0.11 & 0.12 & 10.26 & 5,239 & -0.06 & 0.17 & 5.23 & 1,023 & 0.05 & 0.28 \\
\hline & $\Delta \hat{\theta}$ & SE & & & $\Delta \hat{\theta}$ & SE & & & & \\
\hline \multicolumn{11}{|l|}{ Difference Periods } \\
\hline $1984-1990$ vs. $2007-2016$ & $0.70^{* *}$ & 0.22 & & & & & & & & \\
\hline $1984-1990$ vs. $1997-2006$ & $0.55^{* *}$ & 0.19 & & & & & & & & \\
\hline $1997-2006$ vs. $2007-2016$ & 0.15 & 0.17 & & & 0.10 & 0.25 & & & & \\
\hline
\end{tabular}

Note: Discontinuity estimated for the distribution of the wife's share of household income using a McCrary Test (2008). Restricted to married couples where spouses are between age 25 and 64, where wife and husband have positive annual income, worked at least one month, and are not in education, vocational training, civil service or parental leave, are not self-employed, and do not receive unemployment benefits or pensions in year $t-1$. Cut-off at 0.50001 , bin size 0.05 , optimal (automatic) bandwidth. Averaged over 100 simulation runs based on procedures described in the data section. As annual income is calculated based on answers by survey respondents in the subsequent year, income related statistics for the period 2007-2016 are based on annual incomes between 2007 and 2015. Significance of differences based on two-tailed t-test; ${ }^{* * *} p<0.001,{ }^{* *} p<0.01,{ }^{*} p<0.05,{ }^{\dagger} p<0.1$

For West Germany between 1984 and 1990 (Fig. 1a), the estimated discontinuity at 50 percent of the wife's income share was negative and significant $(p<0.001)$. The distribution dropped by 55.4 percent. Whereas the proportion of wives increases between income shares of 0.2 and 0.5 , the proportion drops abruptly at the point of equal earnings. This result suggests that couples avoided circumstances where the wife earns more than her husband, because the discontinuity at exactly 0.5 is not likely to be just an effect of, for example, assortative mating, working preferences or the gender pay gap. For the later decades, shown in Figures $1 \mathrm{~b}$ and $1 \mathrm{~d}$, the drop decreased to a still significant 23.0 percent $(p=0.02)$ for 1997-2006 and an insignificant 10.3 percent for 2007-2016 ( $p=$ $0.36)$. 


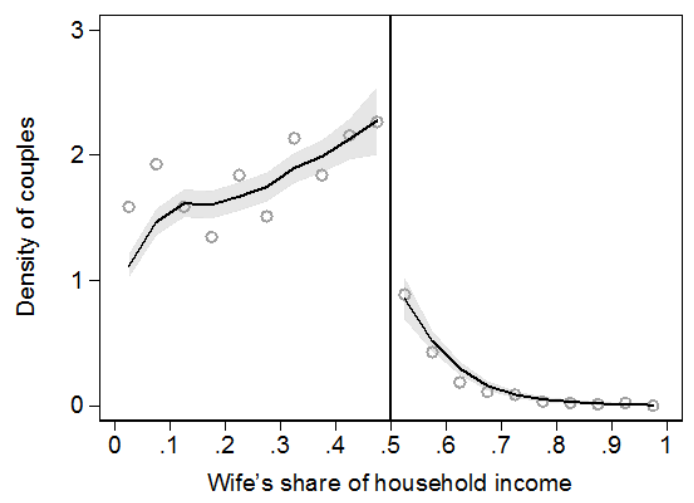

(a) West Germany, 1984-1990

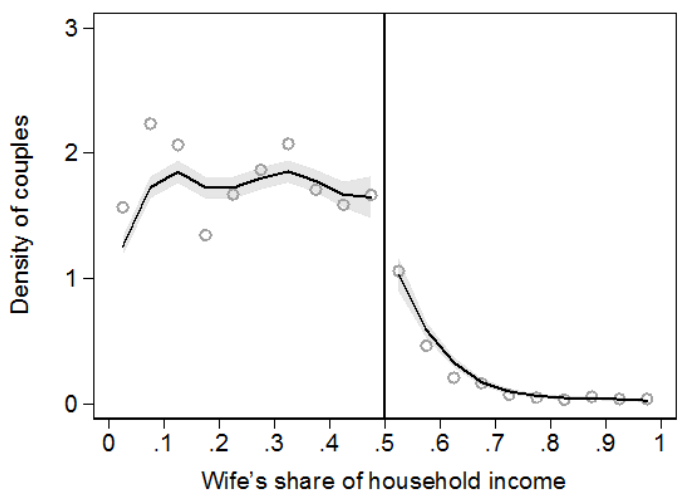

(b) West Germany, 1997-2006

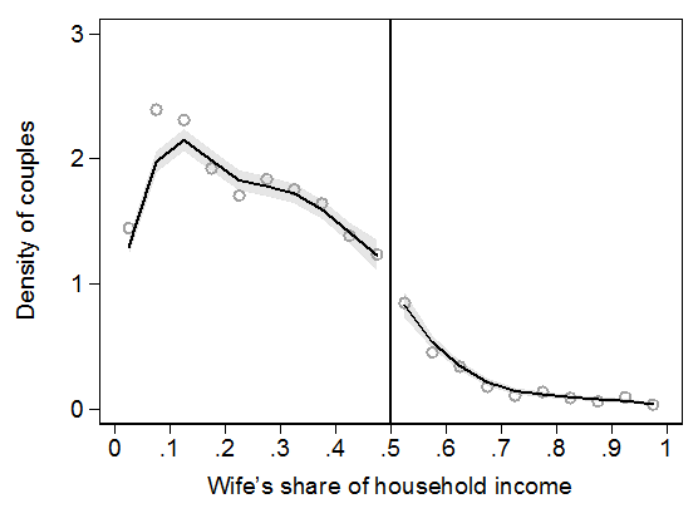

(d) West Germany, 2007-2016

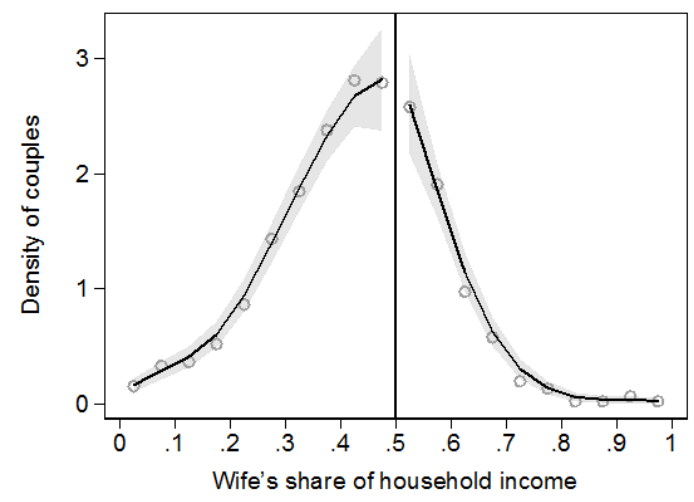

(c) East Germany, 1997-2006

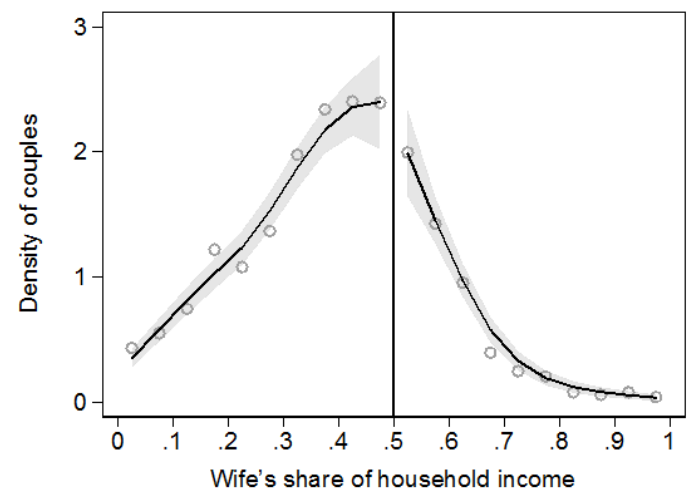

(e) East Germany, 2007-2016

Figure 1. Distribution of relative annual income of wives over time for West and East Germany. Dots reflect the midpoints of a histogram with a bin width of 0.05 , the solid line is the local linear regression smoother allowing for a break at the cut-off, $\mathrm{Cl} 95 \%$. 
The male breadwinner prescription seems to have become less relevant over time in West Germany. A two-sample t-test pairwise comparing the discontinuities between all decades acknowledged a significant decline between 1984-1990 and 2007-2016 ( $p=$ 0.002 , see Table 1). However, the distributions displayed in Figures $1 \mathrm{~b}$ and $1 \mathrm{~d}$ also show that this decline did not correspond to a notable increase in the share of wives who actually earn more than their husbands. Thus, although the 0.5 threshold appears to have lost relevance, the male breadwinner model is still predominant in dual-earner households. The growing shares of women in part-time employment are a likely explanation, which we will review in more detail in the discussion.

For East Germany, we found no significant discontinuities for either 1997-2006 or 2007-2016 (see Table 2). The continuous distribution suggests the persistence of more egalitarian breadwinning prescriptions in the former GDR. This is also reflected in the distributional differences and the substantially higher fraction of female breadwinners compared to West Germany. However, despite the substantial drop delta of almost 30 percentage points for 1997-2006, the discontinuity estimates for West and East Germany were not significantly different from each other. The small sample size for East Germany is a clear constraint in this case. Between 1997-2006 and 2007-2016, the drop in the distribution increased from -4.2 to 5.3 percent for East Germany and was for 2007-2016 of similar size as the drop for West Germany (10.3\%). This convergence might suggest a slight revitalization of a more traditional understanding of gender identity in East Germany under a West German framing. Yet, a two-sample t-test comparing the discontinuities of both decades for East Germany was insignificant.

All in all, our findings confirmed Hypothesis 1, but only for the periods 1984-1990 and 1997-2006. For 2007-2016, the distribution of the wife's share of household income exhibits no significant drop at 50 percent for either West Germany or East Germany.

\subsection{Relative income and labor market outcomes}

One potential reason for the identified discontinuities in the density of relative income is that wives diminish their labor market outcomes in order to restore gender identity conformity after earning more than their husbands. Table 3 presents the effect of a wife's out-earning of her husband in year $t-1$ on three different outcomes in year $t$.

Panel A shows the estimates for the dependent variable wifeEarnsMore, confirming Hypothesis 2a for West Germany 1984-1990 and 1997-2006. For West Germany before reunification, the probability that the wife earned more than her husband in year $t$ was 
significantly decreased by 8.6 percentage points when she out-earned him in the previous year $(p=0.016)$. For $1997-2016$, the effect corresponded to a significant 6.4 percentage point decrease $(p=0.021)$. The effect for $2007-2016$ was still negative and substantial, but no longer significant $\left(\hat{\beta}_{1}=-0.040, p=0.196\right)$. The non-persistent income advantage of female breadwinners might suggest that wives diminished their income to restore the male breadwinner model in these periods. Yet, such behavior appears to have become less prevalent following reunification.

Table 3. Panel regression estimates

\begin{tabular}{|c|c|c|c|c|c|}
\hline & \multicolumn{3}{|c|}{ West Germany } & \multicolumn{2}{|c|}{ East Germany } \\
\hline & (1) & $(2)$ & (3) & (4) & (5) \\
\hline & 1984-1990 & 1997-2006 & 2007-2016 & 1997-2006 & 2007-2016 \\
\hline \multirow{3}{*}{ wifeEarnsMore in $t-1$} & \multicolumn{5}{|c|}{ Panel A - Dependent variable: Wife earns more in $t$} \\
\hline & $-0.086^{*}$ & $-0.064^{*}$ & -0.040 & -0.020 & -0.038 \\
\hline & $(0.036)$ & $(0.027)$ & $(0.030)$ & $(0.034)$ & $(0.043)$ \\
\hline R-squared & 0.023 & 0.013 & 0.014 & 0.019 & 0.022 \\
\hline R-squared (adj.) & 0.018 & 0.010 & 0.012 & 0.009 & 0.011 \\
\hline N (couple-years) & 5,959 & 11,673 & 13,265 & 3,601 & 3,237 \\
\hline \multirow[t]{2}{*}{ n (couples) } & 1,743 & 3,064 & 4,187 & 842 & 877 \\
\hline & \multicolumn{5}{|c|}{ Panel B - Dependent variable: Wife is employed in $t$} \\
\hline \multirow[t]{2}{*}{ wifeEarnsMore in $t-1$} & -0.006 & 0.006 & 0.001 & -0.013 & 0.009 \\
\hline & $(0.015)$ & $(0.009)$ & $(0.008)$ & $(0.008)$ & $(0.008)$ \\
\hline R-squared & 0.085 & 0.109 & 0.030 & 0.063 & 0.055 \\
\hline R-squared (adj.) & 0.080 & 0.106 & 0.026 & 0.053 & 0.044 \\
\hline N (couple-years) & 5,869 & 11,087 & 9,748 & 3,584 & 2,990 \\
\hline \multirow[t]{2}{*}{ n (couples) } & 1,705 & 2,979 & 3,104 & 839 & 795 \\
\hline & \multicolumn{5}{|c|}{ Panel C - Dependent variable: Weekly working hours of wife in $t$} \\
\hline \multirow[t]{2}{*}{ wifeEarnsMore in $t-1$} & $-0.852^{* *}$ & -0.167 & 0.216 & 0.010 & -0.072 \\
\hline & $(0.340)$ & $(0.309)$ & $(0.311)$ & $(0.363)$ & $(0.312)$ \\
\hline R-squared & 0.179 & 0.152 & 0.168 & 0.105 & 0.066 \\
\hline R-squared (adj.) & 0.174 & 0.149 & 0.166 & 0.097 & 0.057 \\
\hline $\mathrm{N}$ (couple-years) & 5,881 & 12,109 & 16,553 & 3,852 & 3,971 \\
\hline n (couples) & 1,744 & 3,385 & 5,015 & 915 & 1,025 \\
\hline
\end{tabular}

Notes: Unweighted regressions with couple fixed effects. wifeEarnsMore is a dummy denoting if the wife earned more than her husband in a given year. Restricted to married couples where spouses are between age 25 and 64, where wife and husband have positive annual income, worked at least one month, and are not in education, vocational training, civil service or parental leave, are not self-employed, and do not receive unemployment benefits or pensions in year $t-1$. All models include a cubic polynomial of the logarithm of the wife's and the husband's annual income, the wife's share of household labor income, and the share of imputed income values for both wife and husband - all at $t-1$. All models include dummies for age groups of 5 years for both spouses, dummy variables for the age of the youngest child in the household, the district level unemployment rate at the month of the interview, and dummy variables for the survey year - all at t. Averaged over 100 simulation runs based on procedures described in the data section. Standard errors clustered on couple level in parentheses; $+p<0.10, * p<0.05, * * p<0.01, * * * p<0.001$.

For East Germany, the wife's estimated probability to earn more than her husband was not significantly associated with out-earning him in the preceding year. The male breadwinner prescription seems to be less relevant in the former GDR. Still, the trend in 
effect sizes across the analysis periods indicates a convergence between West and East Germany.

One extreme way for wives to diminish their income would be for them to leave employment. Panel B presents the estimates of the predicted change in the probability that the wife is in employment in year $t$ when she earned more than her husband in year $\mathrm{t}-$ 1. Our results do not support Hypothesis $2 b$. A wife who out-earned her husband in year t-1 was not less likely to be employed in the subsequent year in any of the analysis periods. In auxiliary estimations we also found no evidence that wives reduced the number of annual months in employment instead.

However, leaving employment is very costly. Thus, wives who earn more than their husbands might prefer to stay employed and reduce their (contractual) working hours to restore traditional gender roles. Panel $\mathrm{C}$ displays the estimated effects on the wife's weekly contractual hours when the wife earned more than her husband in the previous year. Our results are partly in line with Hypothesis $2 c$, at least for West Germany between 1984 and 1990. In this period, the wife's weekly working hours were, on average, reduced by a significant 0.9 hours in year $\mathrm{t}$ if she out-earned her husband in year $\mathrm{t}-1$. For 1997-2006, the effect was only slightly negative and insignificant $\left(\hat{\beta}_{1}=-0.167, p=\right.$ $0.593)$ and even turned positive for 2007-2016 ( $\left.\hat{\beta}_{1}=0.216, p=0.502\right)$. This development might emphasize a trend toward more egalitarian gender prescriptions in West Germany as also suggested by the discontinuity estimations.

\subsection{Robustness}

The estimated discontinuity using the McCrary Test is conditional on several parameters. The chosen bin size of the underlying histogram as well as the bandwidth of the local linear regression estimation affects the fit of the smoothed function. However, we used the optimal bandwidth as proposed by McCrary (2008) with different bin sizes $(0.01,0.02,0.05)$. Overall, we obtained fairly similar estimates (see online appendix Tables C.5-C.6).

Gender identity prescriptions are specific for certain cultures. However, people born outside of Germany are oversampled in several waves of the SOEP. To ensure that the estimated effects were not driven by couples whose gender identity was not shaped by East or West Germany, we repeated our analyses excluding couples where both of the spouses were not born in Germany. Although the loss in sample size resulted in some of the estimated effects becoming insignificant, the respective coefficients remained by 
and large stable (see online appendix Tables C.2 and D.4-D.6).

Moreover, we assigned couples to East or West Germany based on the place of residence at time of the interview. Consequently, couples who were socialized in one part of Germany but subsequently moved to the other might bias our estimates. However, our results were unchanged when we restricted the sample to couples who had not moved to a different part of Germany prior to their interview (see online appendix Tables C.3 and D.7-D.9).

Additionally, not deleting the excess spike of equal earning couples compared to the tax data had no substantial effects on our results (see online appendix Tables C.4 and D.10-D.12). The same was true for the panel regression estimates when using lower order polynomials for the wife's and the husband's income (see online appendix Tables D.13-D.18).

\section{Discussion}

The present paper explored how the gender identity prescription of a male breadwinner affects household economic decisions in East and West Germany. We exploited the unique history of once divided Germany and examined the periods 1984-1990 for West Germany, plus both 1997-2006 and 2007-2016 separately for West and East Germany. Our results suggest that different institutional frameworks shaped rather gendertraditional breadwinner prescriptions in the FRG, today West Germany, and rather gender-egalitarian breadwinner prescriptions in the GDR, today East Germany. Yet, these prescriptions seem to have converged after reunification to an overall rather egalitarian level.

Hypothesis 1 stated that there is a drop in the distribution of the wife's share of household income at the 50 percent threshold for West Germany, because couples avoid the situation where the wife out-earns her husband due to a prevailing male breadwinner norm. This was partly confirmed. The drop in the distribution was highest for 1984-1990, yet continuously declined thereafter and was insignificant for 20072016. For East Germany, the drop was consistently smaller and insignificant. Distinct gender cultures concerning female labor force participation and family breadwinning in the formerly socialist East Germany and the capitalist West Germany potentially account for this difference. However, the development of the discontinuities following reunification suggests an overall convergence between West and East Germany, which is in line with other findings. The much stronger trends for West Germany are presumably both 
an effect of convergence to East Germany as well as an effect of a general trend toward emancipation, including institutionally enhanced labor market opportunities for women. In this perspective, our results are also not necessarily at odds with those of Lee et al. (2007), who found that gender beliefs became more egalitarian in East and West Germany following reunification, but did not converge. Apparently, gender identity prescriptions have always been egalitarian 'enough' in East Germany to make the 50 percent benchmark of wife's relative earnings largely irrelevant, irrespective of any further emancipation.

Hypothesis 2 stated that a couple where the wife out-earns her husband attempts to recover gender identity conformity. We found that a wife who out-earned her husband in year $t-1$ was less likely to do so in year $t$ in West Germany 1984-1990 (-8.6 pp.) and 1997-2006 (-6.4 pp.). This result suggests that wives deliberately diminished their labor market outcomes after earning more than their husbands. In this way, gender identity may explain for Germany why the income advantage of wife breadwinners does not persist for multiple years, as Sarah Winslow-Bowe (2006) reported for the U.S. for a similar period.

We gathered no evidence that this decline in probability to earn more than the husband was due to the wife leaving employment. However, for West Germany 1984-1990, we found that wives who earned more than their husbands at $t-1$ worked 0.9 hours less per week in year t. Apparently, wives rather reduced their working hours instead of (temporarily) leaving employment to earn less than their spouses. No significant effects on the wife's weekly hours were obtained for West Germany for 1997-2006 and 20072016, emphasizing a development toward less traditional gender identity prescriptions in West Germany following reunification. For East Germans, the male breadwinner prescription seemed to be of no particular significance. The wife's out-earning of her husband did not affect her labor market outcomes in any of the analyzed periods.

It remains an open question what drives the decline in breadwinner probability of wives after they out-earned their husbands in West Germany 1997-2006. We found no evidence that wives reduced their working hours or left employment in this period to restore gender identity conformity by diminishing their own income opportunities. Possible explanations might be that wives shifted to lower paying jobs or that husbands relatively increased their income after being out-earned by their wives.

Our results are subject to several limitations. The discontinuity in the distribution of the wife's relative income is only a local indicator around the 50-percent benchmark. If 
wives who earn slightly less than half of the household income switch to part-time work, thus decreasing their income share, then the estimated discontinuity narrows. Consequently, a smaller discontinuity does not necessarily imply a declining relevance of the male breadwinner prescription if increased part-time work is also the result of gender identity prescriptions. However, the increased share of part-time working women since reunification, particularly in West Germany, might rather be an opportunity effect than a gender identity effect. Between 1991 and 2017, the share of women working part-time (<31h per week) increased considerably from 34.3 percent to 48.7 percent in West Germany, and from 17.5 percent to 35.1 percent in East Germany (Hobler \& Pfahl, 2018). This trend indicates enhanced opportunities for wives to work part-time and also explains part of the rise in the female employment rates in West Germany (see also Table 1). Naturally, part-time working wives are less likely to out-earn their almost exclusively full-time working husbands. Only 11 percent of men worked part-time in Germany in 2017, with minor differences between West and East Germany.

Another important issue is that the discontinuity in the distribution of the wife's share of household income might be a result of strategic misreporting of spouses to maintain a male breadwinner arrangement (Murray-Close \& Heggeness, 2018; Roth \& Slotwinski, 2018). In this case, the discontinuity would also reflect a male breadwinner prescription, but it would not derive from wives diminishing their actual income. However, we believe that such misreporting cannot fully explain our findings. Especially for West Germany prior to reunification, the distribution of the wife's relative income and the considerable discontinuity are hardly just the result of an over- and underreporting of husband's and wife's incomes by a few percent. Moreover, the strong trend in discontinuities for West Germany following reunification would also be difficult to explain just by a decline in misreporting. Still, augmenting our analysis by administrative data is a sensible next step for future research.

Further, the limited sample size of the SOEP combined with a region- and periodspecific estimation involves large standard errors and, therefore, an increased probability of type II errors, resulting in an overall rather conservative estimation. In the used fixed effects specification only the change in the variables over time for a given couple is considered. Consequently, variation in wifeEarnsMore was only generated by a change in the income of one of the spouses large enough to move the wife's share of household labor income above the 50 percent threshold. If spouses try to maintain gender identity conformity as the discontinuity plots suggest, then the probability of wives to actually 
cross this threshold is already low. This particularly concerns wives who selected into part-time employment in order to avoid out-earning their husbands in the first place. However, because we differentiated between West and East Germany over different time periods, the sample size of the SOEP was not sufficient to use the imputed likelihood approach of Bertrand et al. (2015). This would have enabled us to consider changes in the wife's imputed probability of earning more than her husband based on the median income of her demographic group in the fixed effects model - instead of analyzing the effect of the wife's actual out-earning of her husband.

The timespan covered by the utilized dataset is also not ideal. Although the SOEP is exceptional for our purpose (no other German panel covers a larger period), it provides no data before 1984 for West Germany and no data before 1990 for East Germany. Thus, we can only extrapolate from our results that the differences in breadwinning prescriptions were probably larger preceding reunification. Using comparable data on both parts of Germany considerably for earlier periods would greatly facilitate the identification of genuine differences and trends. For example, the male breadwinner model was most prevalent in West Germany between the 1950s and 70s (Trappe et al., 2015), presumably also having a stronger impact on the economic decisions of wives in contrast to East Germany at this time.

\section{Conclusion}

Our findings suggest that different institutional frameworks shape distinct and fairly persistent gender identity prescriptions. We found that only couples in West Germany avoided situations where the wife out-earns her husband, suggesting that the male breadwinner prescription was more prevalent in West Germany than in socialist East Germany prior to reunification. After reunification, breadwinner prescriptions appear to have become less traditional in West Germany, converging with the consistently more gender egalitarian East Germany. Thus, household economic decisions are presumably less affected by the male breadwinner model in present-day Germany. Most importantly, this paper makes a strong case that institutions can (slowly) shape domestic

gender cultures and associated identity prescriptions. Although the economically and ideologically driven employment and family policy of the socialist GDR was patriarchal in many respects, some emancipative elements had long lasting effects to the present day. Clearly, using public policy to enhance women's labor market participation and economic opportunities is one important contribution to gender equality. 


\section{References}

Adler, M. A., \& Brayfield, A. (1996). East-West Differences in Attitudes About Employment and Family in Germany. The Sociological Quarterly, 37(2), 245-260. https://doi.org/10/d5qf4r

Aisenbrey, S., \& Fasang, A. (2017). The interplay of work and family trajectories over the life course: Germany and the United States in comparison. American Journal of Sociology, 122(5), 1448-1484. https://doi.org/10/f934m7

Akerlof, G. A., \& Kranton, R. E. (2000). Economics And Identity. The Quarterly Journal of Economics, MIT Press, 115(3), 715-753. https://doi.org/10/fxdw82

Akerlof, G. A., \& Kranton, R. E. (2010). Identity Economics. Princeton and Oxford: Princeton University Press.

Anxo, D., Fagan, C., Cebrian, I., \& Moreno, G. (2007). Patterns of labour market integration in Europe-a life course perspective on time policies. Socio-Economic Review, 5(2), 233-260. https://doi.org/10/fg2cfw

Becker, G. S. (1991). A Treatise on the Family. Cambridge, Massachusetts: Harvard University Press.

Bertrand, M., Kamenica, E., \& Pan, J. (2015). Gender Identity and Relative Income within Households. The Quarterly Journal of Economics, 130(2), 571-614. https://doi.org/10/f7c9hw

Binder, A. J., \& Lam, D. (2018). Is There a Male Breadwinner Norm? The Hazards of Inferring Preferences from Marriage Market Outcomes (Working Paper No. 24907). https://doi.org/10.3386/w24907

Brady, D., Blome, A., \& Kmec, J. A. (2019). Work-family reconciliation policies and women's and mothers' labor market outcomes in rich democracies. Socio-Economic Review. https://doi.org/10/gft4pv

Cha, Y., \& Thébaud, S. (2009). Labor Markets, Breadwinning, and Beliefs: How Economic Context Shapes Men's Gender Ideology. Gender \& Society, 23(2), 215-243. https://doi.org/10/db5xf3

Codazzi, K., Pero, V. L., \& Sant'Anna, A. (2017). Gender identity and female labour supply in Brazil. WIDER Working Paper.

Cooke, L. P. (2007). Persistent Policy Effects on the Division of Domestic Tasks in Reunified Germany. Journal of Marriage and Family, 69(4), 930-950. https://doi.org/10/chq98j

Destatis. (2019). Unbereinigter Gender Pay Gap nach Gebietsstand. Retrieved April 3, 2019, from Statistisches Bundesamt website: https://www.destatis.de/DE/Themen/Arbeit/Verdienste/Verdienste-Verdienstunterschiede/Tabellen/ugpg-01-gebietsstand.html

Duggan, L. (1995). Restacking the deck: Family policy and women's fall-back position in Germany before and after unification. Feminist Economics, 1(1), 175-194. https://doi.org/10/c4ctv3

Görges, L., \& Beblo, M. (2015). Breaking down the wall between nature and nurture: An exploration of gendered work preferences in East and West Germany. Retrieved from https://www.econstor.eu/handle/10419/112825 
Gornick, J. C. (2004). Women's economic outcomes, gender inequality and public policy: findings from the Luxembourg Income Study. Socio-Economic Review, 2(2), 213-238. https://doi.org/10/bxk433

Gottfried, H., \& O'Reilly, J. (2002). Reregulating breadwinner models in socially conservative welfare systems: comparing Germany and Japan. Social Politics: International Studies in Gender, State \& Society, 9(1), 29-59. https://doi.org/10/b5cgwx

Hederos Eriksson, K., \& Stenberg, A. (2015). Gender Identity and Relative Income within Households: Evidence from Sweden. IZA Discussion Paper Series, (9533).

Helwig, G. (1993). Einleitung. In Bundeszentrale für politische Bildung (Ed.), Frauen in Deutschland 1945-1992 (pp. 9-22). Helwig, Gisela and Nickel, Hidelgard Maria.

Hipp, L., Bernhardt, J., \& Allmendinger, J. (2015). Institutions and the prevalence of nonstandard employment. Socio-Economic Review, 13(2), 351-377. https://doi.org/10/gft4px

Hobler, D., \& Pfahl, S. (2018). Teilzeitquoten der abhängig Beschäftigten 1991-2017 (No. AZ06; p. 10). Retrieved from Wirtschafts- und Sozialwissenschaftliches Institut website: https://media.boeckler.de/Sites/A/Online-Archiv/24129

Hummelsheim, D., \& Hirschle, J. (2010). Mother's Employment: Cultural Imprint or Institutional Governance? European Societies, 12(3), 339-366. https://doi.org/10/cqfj3k

Kelle, N., Simonson, J., \& Gordo, L. R. (2017). Is Part-Time Employment after Childbirth a Stepping-Stone into Full-Time Work? A Cohort Study for East and West Germany. Feminist Economics, 23(4), 201-224. https://doi.org/10/gfs3z8

Kronmal, R. A. (1993). Spurious Correlation and the Fallacy of the Ratio Standard Revisited. Journal of the Royal Statistical Society. Series A (Statistics in Society), 156(3), 379-392. https://doi.org/10/c2jvgc

Lee, K. S., Alwin, D. F., \& Tufiş, P. A. (2007). Beliefs about Women's Labour in the Reunified Germany, 1991-2004. European Sociological Review, 23(4), 487-503. https://doi.org/10/d8t5qn

Lippmann, Q., Georgieff, A., \& Senik, C. (2016). Undoing Gender with Institutions. Lessons from the German Division and Reunification (No. 2016-06). Retrieved from https://halshs.archives-ouvertes.fr/halshs-01297653

McCrary, J. (2008). Manipulation of the running variable in the regression discontinuity design: A density test. Journal of Econometrics, 142(2), 698-714. https://doi.org/10/fbrkqk

Murray-Close, M., \& Heggeness, M. L. (2018). Manning up and womaning down: How husbands and wives report their earnings when she earns more. SESHD Working Paper, (2018-20), 18.

Nickel, H. M. (1992). "Mitgestalterinnen des Sozialismus" - Frauenarbeit in der DDR. In Bundeszentrale für politische Bildung (Ed.), Frauen in Deutschland 1945-1992 (pp. 233-256).

Nyman, C., Reinikainen, L., \& Stocks, J. (2013). Reflections on a Cross-National Qualitative Study of Within-Household Finances. Journal of Marriage and Family, 75(3), 640-650. https://doi.org/10/f22r77 
Pfau-Effinger, B. (2012). Women's employment in the institutional and cultural context. International Journal of Sociology and Social Policy, 32(9/10), 530-543. https://doi.org/10/gft4qr

Pfau-Effinger, B., \& Smidt, M. (2011). Differences in women's employment patterns and family policies: eastern and western Germany. Community, Work \& Family, 14(2), 217-232. https://doi.org/10/b4skcc

Rosenfeld, R. A., Trappe, H., \& Gornick, J. C. (2004). Gender and work in Germany: Before and after reunification. Annu. Rev. Sociol., 30, 103-124. https://doi.org/10/cqmkrq

Roth, A., \& Slotwinski, M. (2018). Gender norms and income misreporting within households. CESifo Working Paper, (7298), 30.

Steiber, N., \& Haas, B. (2009). Ideals or compromises? The attitude-behaviour relationship in mothers' employment. Socio-Economic Review, 7(4), 639-668. https://doi.org/10/dj4tzc

Steiber, N., \& Haas, B. (2012). Advances in explaining women's employment patterns. Socio-Economic Review, 10(2), 343-367. https://doi.org/10/gfs33d

Trappe, H., Pollmann-Schult, M., \& Schmitt, C. (2015). The rise and decline of the male breadwinner model: institutional underpinnings and future expectations. European Sociological Review, 31(2), 230-242. https://doi.org/10/f7ds45

Trappe, H., \& Sørensen, A. (2006). Economic Relations Between Women and Their Partners: An East and West German Comparison After Reunification. Feminist Economics, 12(4), 643-665. https://doi.org/10/bjtqsd

Wagner, G., Frick, J., \& Schupp, J. (2007). The German Socio-Economic Panel Study (SOEP) Scope, Evolution and Enhancements. Schmollers Jahrbuch, 127(1), 139-169.

West, C., \& Zimmerman, D. H. (1987). Doing Gender. Gender and Society, 1(2), 125-151. https://doi.org/10/bm4wnp

Winslow-Bowe, S. (2006). The Persistence of Wives' Income Advantage. Journal of Marriage and Family, 68(4), 824-842. https://doi.org/10/ctx96n

Zinovyeva, N., \& Tverdostup, M. (2018). Gender Identity, Co-Working Spouses and Relative Income within Households (No. 11757). Retrieved from Institute for the Study of Labor (IZA) website: https://ideas.repec.org/p/iza/izadps/dp11757.html

\section{Online appendix}

Please view or download the online appendix materials using the following link:

\section{https://box.hu-berlin.de/f/28951131a61d41db93b1/}

